\title{
Article
}

\section{Analysis of Earth Pressure Variation for Partial Displacement of Retaining Wall}

\author{
Hongbo Zhang ${ }^{1}{ }^{\mathbb{D}}$, Mingpeng Liu ${ }^{1}$, Pengfei Zhou ${ }^{2}$, Zhizhong Zhao ${ }^{3, *}$, Xiaoliang Li ${ }^{4}$, Xiaobin Xu ${ }^{2}$ \\ and Xiuguang Song ${ }^{1, *}$ \\ 1 School of Qilu Transportation, Shandong University, Jinan 250061, China; zhanghongbo@sdu.edu.cn (H.Z.); \\ 201914985@mail.sdu.edu.cn (M.L.) \\ 2 Shandong Hi-Speed Group Co., Ltd., Jinan 250001, China; pengfeizhou@163.com (P.Z.); \\ csxx1123a@126.com (X.X.) \\ 3 School of Civil Engineering, Shandong Jiaotong University, Jinan 250023, China \\ 4 Shandong Hi-Speed Company Limited, Jinan 250014,China; lixiaoliang_sd@163.com \\ * Correspondence: zhaozhizhong@sdjtu.edu.cn (Z.Z.); songxiuguang@sdu.edu.cn (X.S.)
}

Citation: Zhang, H.; Liu, M.;

Zhou, P.; Zhao, Z.; Li, X.; Xu, X.;

Song, X. Analysis of Earth Pressure

Variation for Partial Displacement of Retaining Wall. Appl. Sci. 2021, 11,

4152. https://doi.org/10.3390/

app11094152

Academic Editor:

Giuseppe Lacidogna

Received: 17 April 2021

Accepted: 29 April 2021

Published: 1 May 2021

Publisher's Note: MDPI stays neutral with regard to jurisdictional claims in published maps and institutional affiliations.

Copyright: (C) 2021 by the authors. Licensee MDPI, Basel, Switzerland. This article is an open access article distributed under the terms and conditions of the Creative Commons Attribution (CC BY) license (https:// creativecommons.org/licenses/by/ $4.0 /)$.

\begin{abstract}
Parts of the retaining wall might produce displacement under different load conditions. The moveable wall could impact the adjacent fixed wall, mainly reflecting on the variation of earth pressure and formation of the soil arching effect. This paper conducted the horizontal trap-door test to explore the variation of active earth pressure caused by partial displacement of the retaining wall. Different trap-door width and three displacement modes were addressed as the influence factors. The results indicated that the horizontal soil arching effect was generated after the active displacement of the trap-door and the soil pressure was redistributed. The distribution of lateral soil pressure was approximately an "inverted bell" curve. For trap-door widths of $20 \mathrm{~cm}, 30 \mathrm{~cm}$, and $40 \mathrm{~cm}$, a secondary soil arching effect appeared in the test. The relationship between lateral earth pressure and displacement was different with the traditional limited theory due to the influence of the soil arching effect. The variation curve of earth pressure corresponding to displacement could be divided into three stages. In addition, the distribution of earth pressure along the trap-door height was non-linear. Trap-door width can significantly influence the maximum earth pressure on the fixed wall and the range where pressure changes. Finally, the effect of load sharing was explored and found to be related with displacement and width of trap-door as well as the displacement mode.
\end{abstract}

Keywords: retaining wall; partial displacement; horizontal trap-door test; active earth pressure; soil arching effect; loading sharing ratio

\section{Introduction}

Retaining wall has been widely used in transportation, water conservancy, and construction projects [1]. However, part of the retaining wall might produce differential movement due to the influence of different stiffness of wall, embedding depth, foundation overload, and the constraint of the wall end [2]. According to Fang et al. [3,4], the displacement pattern of the retaining wall was simplified into three types: translation (T), rotation around the top (RT), and rotation around the base (RB). The movement of the retaining wall can lead to subgrade disasters such as longitudinal cracking, settlements, and slip of embankment, as shown in Figure 1 and further cause serious engineering accidents. In realistic roads, there is usually a part of the retaining wall producing displacement along the longitudinal road. However, previous research has mainly focused on the movement of the entire longitudinal retaining wall [5], which is inconsistent with the reality. The partial moveable wall could heavily affect the adjacent stationary wall, but there are still only a few studies concentrating on the influence of the partial displacement of the retaining wall [6]. 


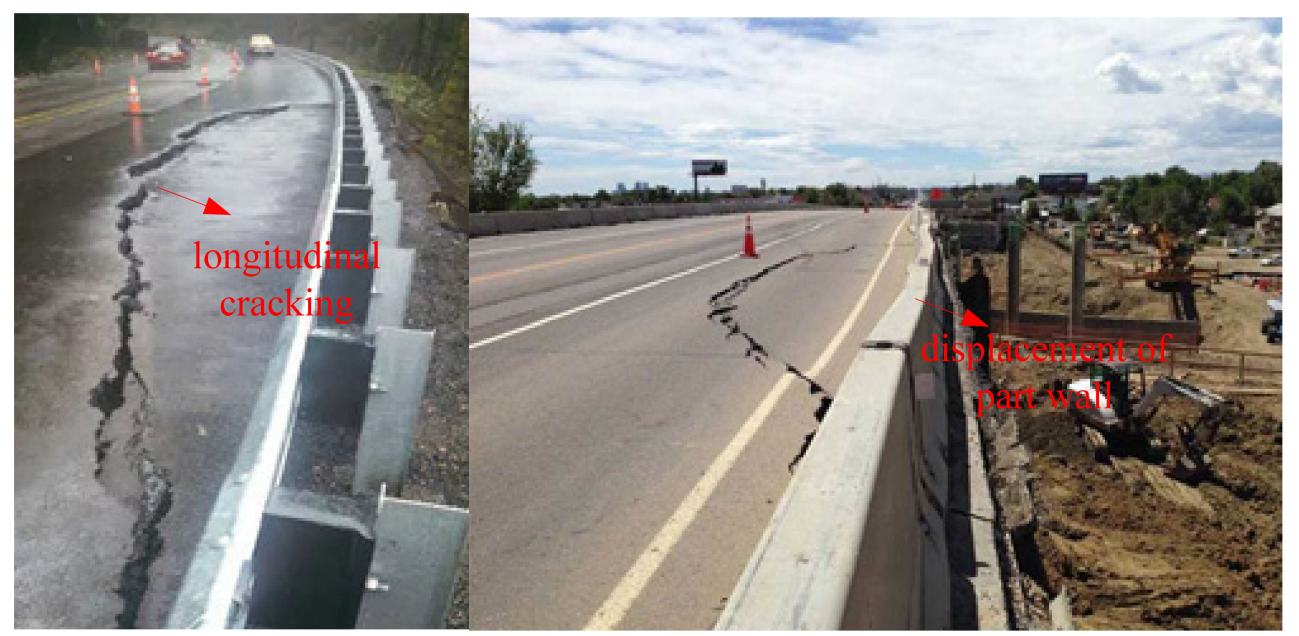

(a)

(b)

Figure 1. Disaster caused by partial displacement of retaining wall. (a) longitudinal cracking, (b) displacement of part retaining wall.

Meanwhile, when the partial wall produces displacement, there is usually uneven deformation of the soil behind the retaining wall. As a result, the soil arching effect can be generated [7], which causes the variation of earth pressure behind both the moveable wall and adjacent stationary wall. Changes in earth pressure could cause significant impact on the stability of the wall. Thus, to reveal the relationship between uneven deformation of soil and earth pressure behind the wall, the concept of the soil arching effect was raised [8-10]. The soil arching effect is widespread in the field of geotechnical engineering. Terzaghi [11] first verified the existence of the soil arching by the trap-door test, and defined it as the phenomenon of stress transformation from the yielding soil to the stationary soil. Then, McNulty [12], Ladanyi and Hoyaux [13], and Pardo and Sáez [14] obtained similar results to Terzaghi by conducting trap-door tests. Handy [15] and Adachi [16] revealed the mechanism and influencing factors of soil arching both in sand and clay by considering active and passive displacement modes. Dewoolkar et al. [17] found that the soil arch changed with the development of the deformation of the trap-door. On the contrary, it underwent the process of formation-destruction-reformation. As a result, the earth pressure on the trap-door first decreased, then increased until it was stabilized in the end. Papamicho et al. [18], Iglesia et al. [19], and Chevalier et al. [20] also verified this phenomenon.

Most of the studies about soil arching have been based on the vertical trap-door test. For the retaining wall, the horizontal soil arching can control the distribution of the lateral load. In order to verify the existence of the lateral soil arching effect, Wang et al. [21], Kahyaoğlu et al. [22], He et al. [23], and Chen and Martin [24] did a lot of analysis by adopting theoretical analysis, scaled model experiments, numerical simulation, or field monitoring. Bosscher and Gray [25] carried out the horizontal arching test in slope and found the load on the gate between piles first decreased and then increased to a steady value with the increasing gate deformation. Li et al. [26] found that the distribution of earth pressure presented as an inverted-bell curve along the horizontal direction due to soil arching. Similarly, Huang et al. [27] discovered that the lateral soil arching between piles could cause the nonlinear distribution of active earth pressure on sheet pile walls. Bakri et al. [28] presented a three-dimensional model of the load sharing ratio based on horizontal soil arching, which could reflect the reduction of the pressure of the surrounding soil and the enlargement of the load exertion on piles. In summary, the earth pressure would be greatly influenced by the lateral soil arching. However, most of above-mentioned studies barely conducted research about the horizontal soil arching effect of the retaining wall in the case of partial displacement, and also did not consider the influence of movement modes such as T, RB, and RT modes. 
In this study, horizontal trap-door tests were carried out to investigate the influence of the displacement of the partial wall. The width of the trap-door and three different movement modes ( $\mathrm{T}, \mathrm{RB}$, and RT) were taken as the influence factors in these tests. The distribution of lateral earth pressure under three movement modes are discussed in detail. The variation of horizontal earth pressure with displacement and along the height were also researched, respectively. The soil arching effect during the experiment was studied to explain the variation of earth pressure. The influence of the trap-door width and the load sharing ratio were considered to further illustrate the effect of the partial moveable wall.

\section{Materials and Testing Procedures}

\subsection{Experimental Setup}

To determine the distribution of earth pressure behind the moveable wall and fixed wall, a series of trap-door tests were conducted on a model test apparatus, as shown in Figure 2. The test box was made of steel, with dimensions of $2.5 \times 0.5 \times 0.5 \mathrm{~m}$ (length, width, and height, respectively). The purpose of this design was to eliminate 'size effect' and cover the influence range of mobile plates. The trap-door apparatus was located at the middle of one side of the box wall and was composed of four movable plates with a $10 \mathrm{~cm}$ width. The upper and lower ends of each movable plate were respectively jointed with one lever. These levers could be fixed or rotated to induce different displacement modes and distance of movable doors. To detect the horizontal earth pressure, stress detectors with an accuracy of $0.01 \mathrm{kPa}$ were arranged at different heights on the movable plates and fixed wall, as shown in Figure 3. The type of stress detectors used in the experiment was a strain-acquisition instrument with a diameter of $20 \mathrm{~mm}$ produced by Donghua Company, as shown in Figure 3. To limit the detector connectors, the stress detectors were arranged on the left side. According to the symmetry criteria and study of Cui [6], the earth pressure on the right side could be recorded symmetrically.

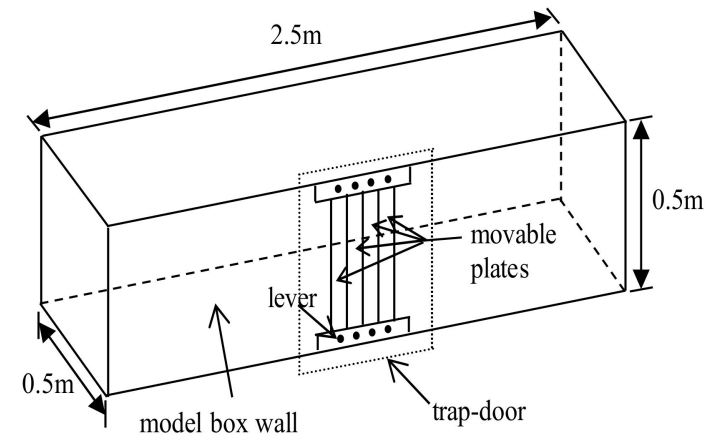

(a)

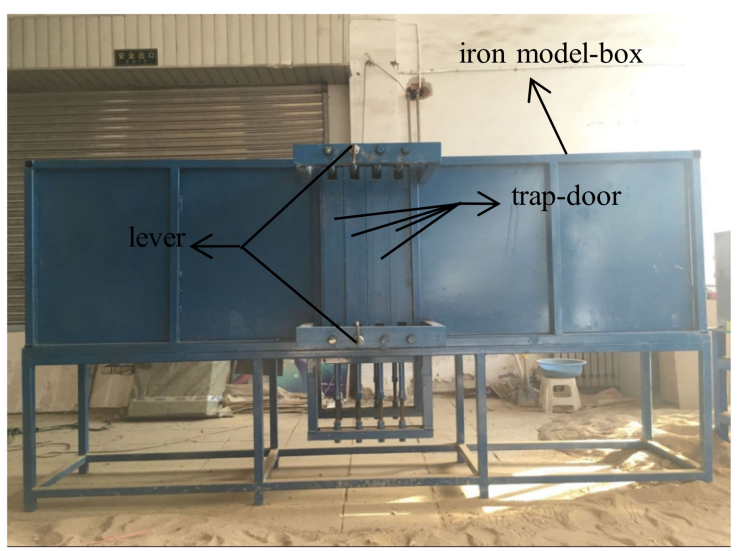

(b)

Figure 2. Trap-door experiment apparatus. (a) Schematic diagram of the test facility, (b) Physical map of the test facility.

\subsection{Material}

Dry sand from the Yellow River, Shandong Province, China was used as the filler in the test. The grading curve of the sample sand is shown in Figure 4. Before the test, the sand was dried in a drying room for over $24 \mathrm{~h}$ to eliminate the influence of moisture content on soil strength. The effective particle size $d_{10}$, and constrained diameter $d_{60}$ and $d_{30}$ of sample sand were $0.12 \mathrm{~mm}, 0.82 \mathrm{~mm}$, and $0.36 \mathrm{~mm}$, respectively. The uniformity coefficient of the sample sand was 5.47 and the coefficient of curvature was 1.32. According to the Standard for Geotechnical Testing Method (GB/T 50123-2019) [29], the fineness modulus MX was 2.435 , which means that the sand belonged to medium sand. The physical properties of the sand samples are given in Table 1. 


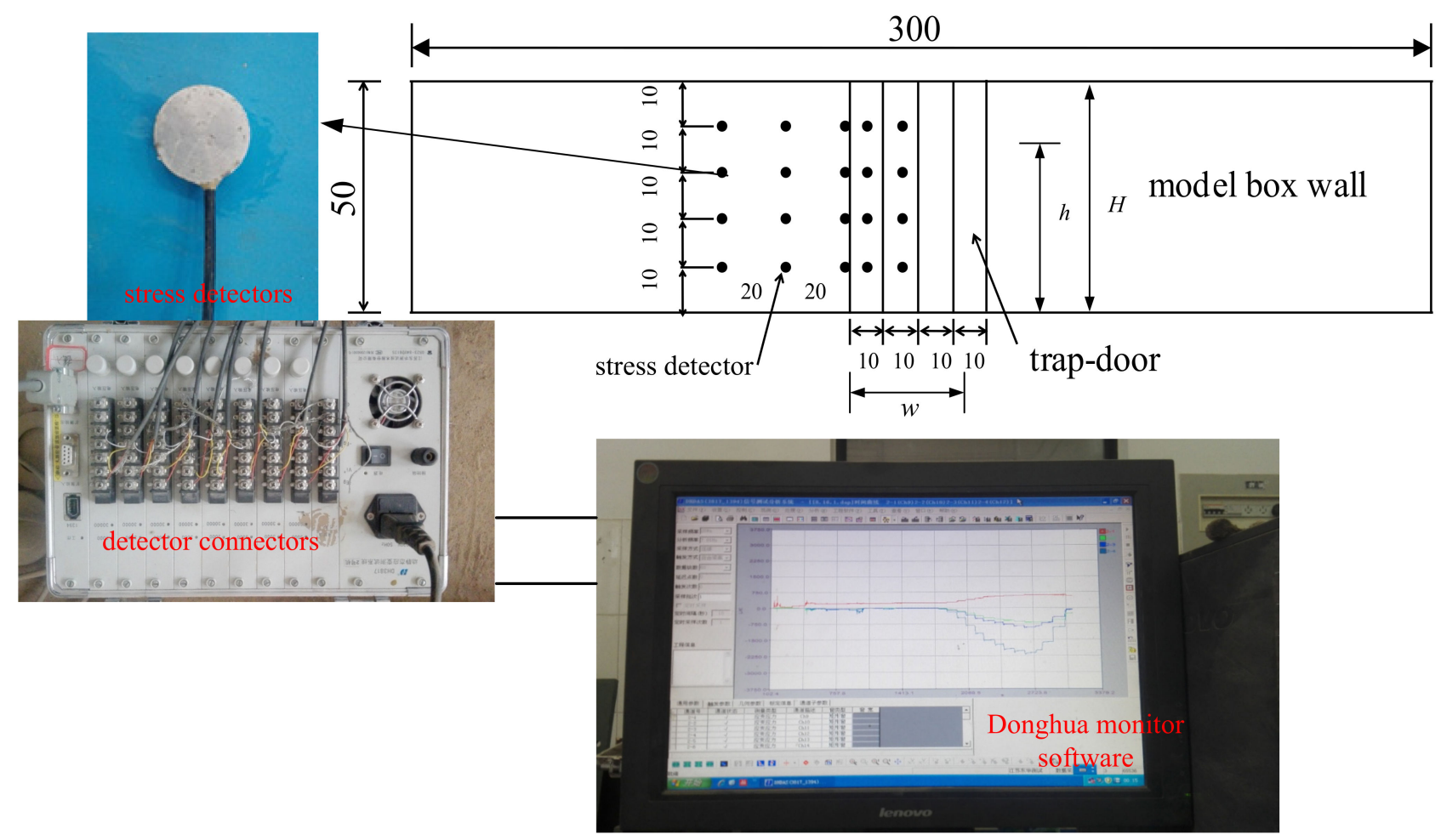

Figure 3. Distribution of earth pressure detectors and data acquisition scheme (unit length: $\mathrm{cm}$ ).

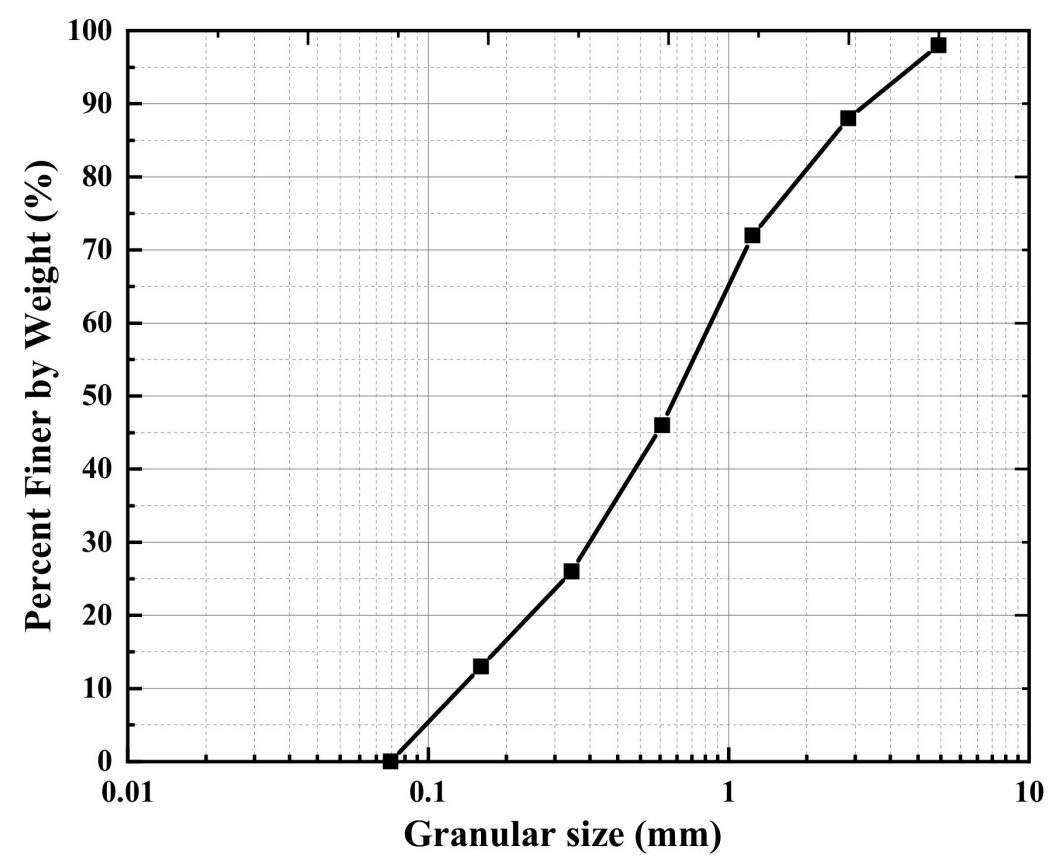

Figure 4. Grading curve of the sample sand.

Table 1. Property of the test sand.

\begin{tabular}{cccccc}
\hline Poisson's Ratio & Specific Gravity & $\begin{array}{c}\text { Internal Friction } \\
\text { Angle }\left({ }^{\circ}\right)\end{array}$ & $\begin{array}{c}\text { Maximum Dry } \\
\text { Density }\left(\mathbf{g} / \mathbf{c m}^{3}\right)\end{array}$ & $\begin{array}{c}\text { Minimum Dry } \\
\text { Density }\left(\mathbf{g} / \mathbf{c m}^{3}\right)\end{array}$ & $\begin{array}{c}\text { Measured Bulk } \\
\text { Density }\left(\mathbf{g} / \mathbf{c m}^{3}\right)\end{array}$ \\
\hline 0.35 & 2.67 & 38 & 1.82 & 1.17 & 1.685 \\
\hline
\end{tabular}




\subsection{Test Procedures}

The sand was filled and compacted in layers with a height of $10 \mathrm{~cm}$ each time. During filling, the relative compactness of each layer was controlled to be 0.75 . According to the Standard for Geotechnical Testing Method (GB/T 50123-2019), the compactness of sand $D_{\mathrm{r}}$ is controlled by the relative density, as shown in Equation (1).

$$
D_{\mathrm{r}}=\frac{\rho_{\mathrm{dmax}}\left(\rho_{\mathrm{d}}-\rho_{\mathrm{dmin}}\right)}{\rho_{\mathrm{d}}\left(\rho_{\mathrm{dmax}}-\rho_{\mathrm{dmin}}\right)}
$$

where $\rho_{\mathrm{dmax}}$ is the maximum dry density of sand; $\rho_{\mathrm{dmin}}$ is the minimum dry density; and $\rho_{\mathrm{d}}$ is the actual dry density of the soil. By equating $D_{\mathrm{r}}$ in Equation (1) to 0.75 , the actual dry density of the sand can be calculated ( $\rho_{\mathrm{dmax}}$ and $\rho_{\mathrm{dmin}}$ are shown in Table 1$)$. Accompanied with the already-known volume of each filling, thus the relative compactness of each layer can be controlled by the mass of sand in each filling.

The sand around the stress detectors was tamped with a rubber hammer to minimize the impact on the stress detectors. To control the movement precisely, the displacement was applied by rotating the levers. A diagram of multi-stage movement in three displacement modes is shown in Figure 5. The trap-door could move outward by rotating the lever and rotating the lever; one lap could achieve a $0.5 \mathrm{~mm}$ distance of the trap-door. Therefore, the distance can be controlled by the number of rotating laps. Thereby, rotating the top lever and fixing the bottom lever corresponded to the RB mode and rotating the bottom lever and fixing the upper lever achieved RT mode. Rotating both the top lever and bottom lever for the same laps could realize T mode. Regarding the movement level as $N$, the $N$-level displacement amount can be referred to as $\Delta=N \times 0.5(\mathrm{~mm})$ with every $0.5 \mathrm{~mm}$ increment.

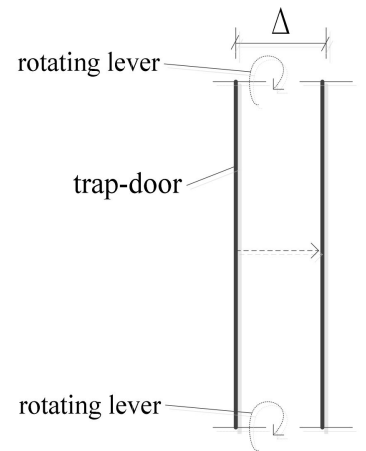

(a)

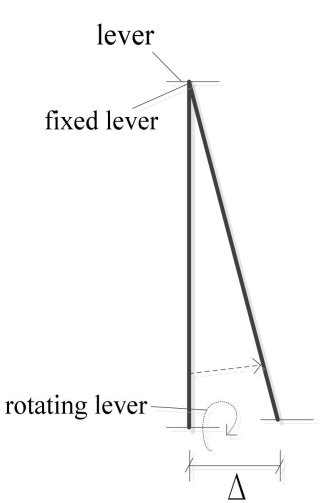

(b)

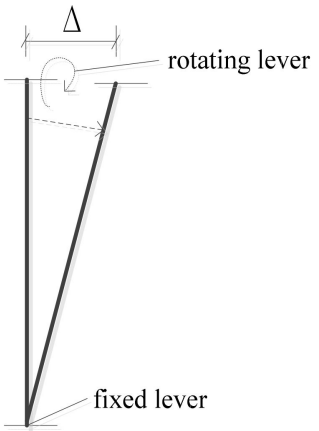

(c)

Figure 5. Diagram of multi-stage loading in three displacement modes: (a) T mode, (b) RT mode, (c) RB mode.

After each movement step of the movable plates, the earth pressure was measured by the Donghua monitor software shown in Figure 3 when the number of stress detectors was stabilized. All the test conditions are listed in Table 2 and the experiment process is shown in Figure 6.

Table 2. Test condition of the horizontal trap-door test.

\begin{tabular}{ccccc}
\hline Test Condition & Width of Trap-Door $\mathbf{( c m )}$ & Movement Mode & Filler Height $(\mathbf{c m})$ & $N$-Level Distance $(\mathbf{m m})$ \\
\hline $1 \sim 3$ & 10 & T, RT, RB & 50 & $0.5 \times N$ \\
$4 \sim 6$ & 20 & T, RT, RB & 50 & $0.5 \times N$ \\
$7 \sim 9$ & 30 & T, RT, RB & 50 & $0.5 \times N$ \\
$10 \sim 12$ & 40 & T, RT, RB & 50 & $0.5 \times \mathrm{N}$ \\
\hline
\end{tabular}




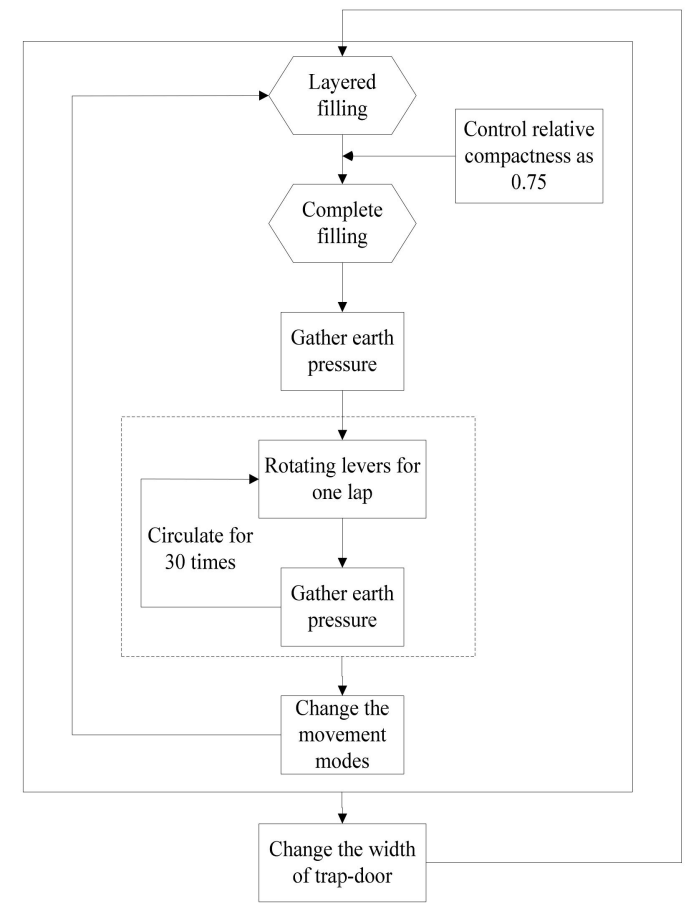

Figure 6. Experimental process.

\section{Results and Discussion}

\subsection{Distribution of Lateral Earth Pressure in T Mode}

As shown in Figure 7, the coordinate of schematic diagrams of the trap-door test was determined and is discussed in the following. The center of the movable plates for each trap-door test was selected as the zero point of the abscissa. The earth pressure at the height of $30 \mathrm{~cm}$ was selected for analysis while the data at other heights were similar. The maximum distance of the trap-door was marked as $S_{\max }$, the height of the trap-door was noted as $H$, and the width of trap-door was $w$, as shown in Figure 3. The coordinate diagrams in other displacement modes were the same. Because the load cells were only arranged on the semi-length wall, the earth pressure data on the other half length could be recorded symmetrically.

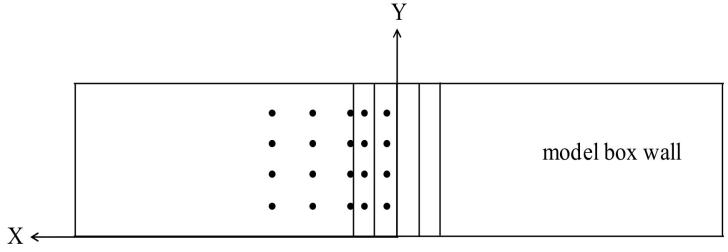

(a)

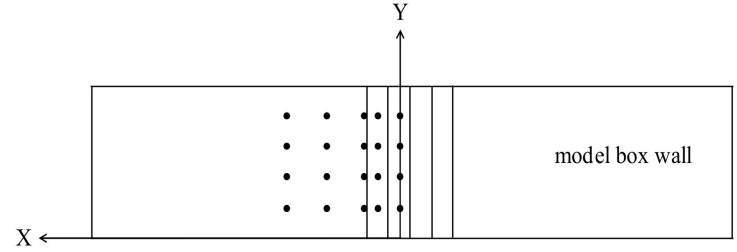

(b)

Figure 7. Schematic diagrams of coordinate axes. (a) The width of trap-door was $20 \mathrm{~cm}$ and $40 \mathrm{~cm}$. (b) The width of trap-door was $10 \mathrm{~cm}$ and $30 \mathrm{~cm}$.

The distribution of the lateral earth pressure along the $X$ axis under the condition of different widths of T mode is shown in Figure 8. Once moveable plates of any width produced an outward translation movement, earth pressure behind them decreased rapidly. With the development of movement, the minimal pressure behind moveable plates approached 0 . However, the earth pressure behind the fixed wall increased sharply and surpassed the static earth pressure. It can be seen that the distribution of the lateral soil pressure along the X axis was approximately an "inverted bell" curve. The gap of peak pressure behind the fixed wall in different trap-door widths was less than $11 \%$. 


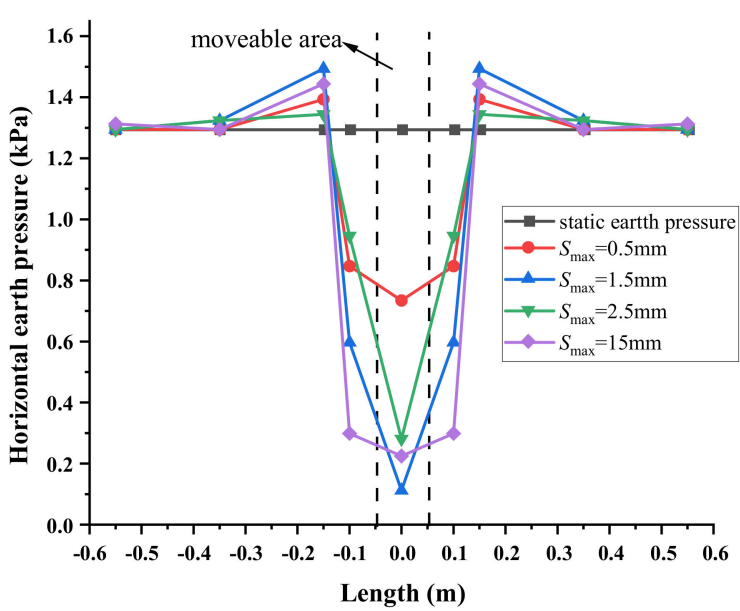

(a)

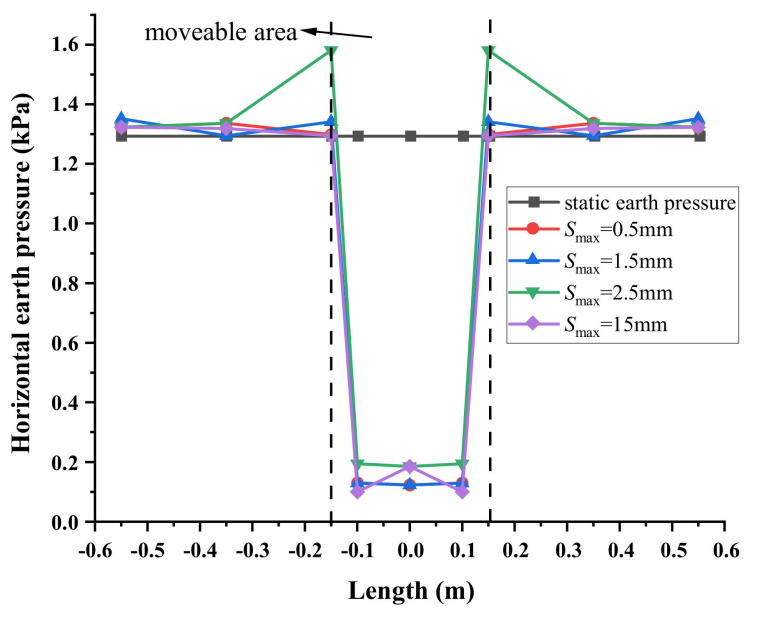

(c)

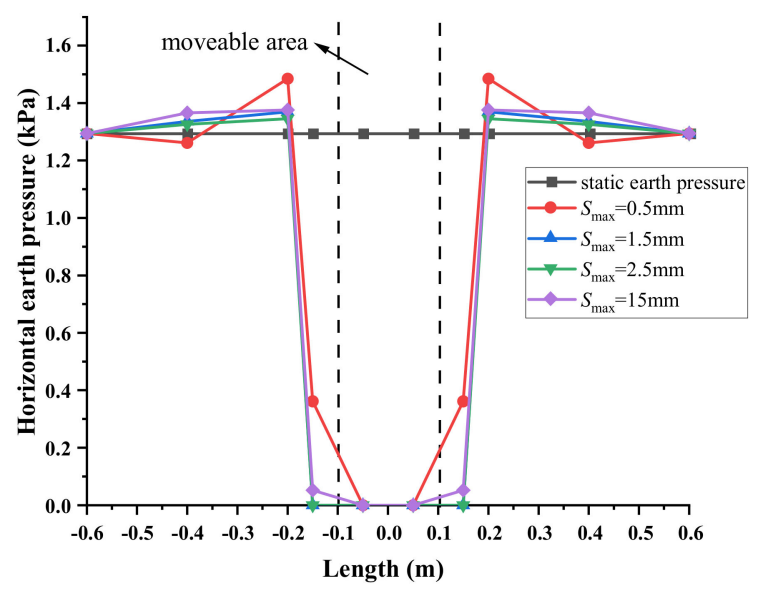

(b)

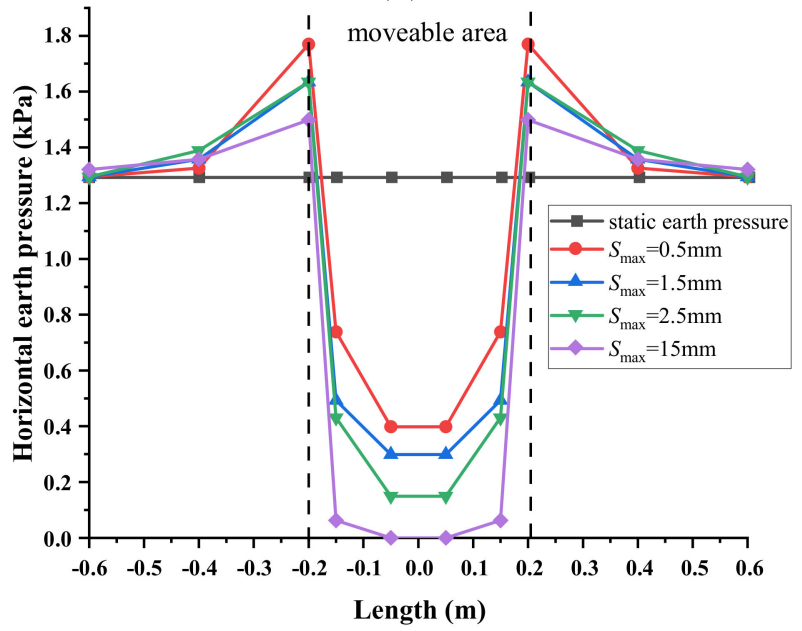

(d)

Figure 8. The distribution of earth pressure along the $\mathrm{X}$ axis with different trap-door widths in T-mode: $(\mathbf{a}) w / H=0.2$, (b) $w / H=0.4,(\mathbf{c}) w / H=0.6,(\mathbf{d}) w / H=0.8$.

The primary reason accounting to this phenomenon is uneven deformation of the soil, which meant that the deformation of soil behind the movable plates was larger than that behind the fixed wall. The horizontal soil arching effect was thus generated in the soil body [6], as shown in Figure 9a. The soil arching effect can redistribute the soil stress and can fully mobilize the shear strength. The shearing resistance caused by uneven displacement reduced the earth pressure on the yielding soil and increased the pressure on the adjoining stationary part. The redistribution of earth pressure behind the movable plates and fixed wall, as shown in Figure $9 b$, revealed that the earth pressure behind moveable plates would be lower than the static earth pressure, $p_{0}=k_{0} \gamma h$. However, the earth pressure behind the fixed wall would be higher than the static earth pressure, $p_{0}$.

\subsection{Distribution of Lateral Earth Pressure in RB Mode}

The distribution of the lateral earth pressure along the $X$ axis in RB mode is shown in Figure 10. Similar to T mode, the variation of earth pressure behind the moveable plates and fixed wall along the $X$ axis was also like an inverted bell, which showed that the horizontal soil arching also existed in RB mode. However, it should be noted that the minimum value of the lateral soil pressure behind moveable plates was not located at the middle width of the trap-door but near the side of the moveable area. In comparison with Figure 8, there were three peak values of lateral earth pressure in this movement mode. The peak pressure at the middle trap-door in RB mode was much higher than that in $\mathrm{T}$ mode. It can be explained that the soil in the width-range of the trap-door might produce 
a 'secondary soil arching effect' that was derived from the experiment of Chevalier [20], as presented in Figures 11 and 12. The secondary soil arching effect would dominate the stress redistribution of the soil between the 'main soil arch' and the trap-door. Therefore, the minimum lateral soil pressure was near the edge of the movable plates.

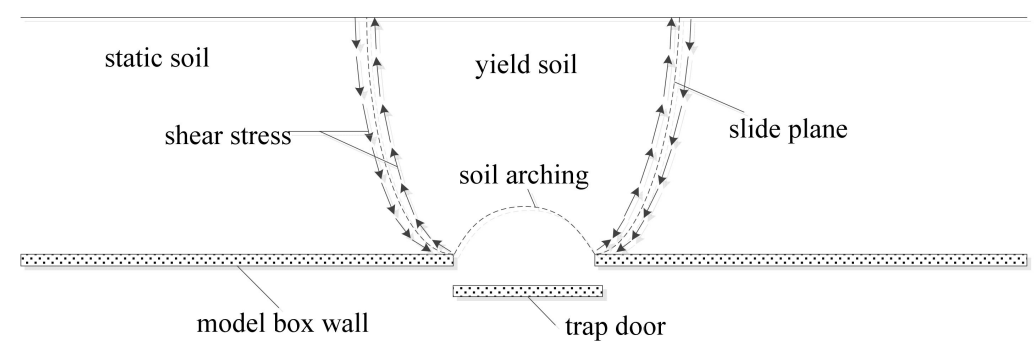

(a)

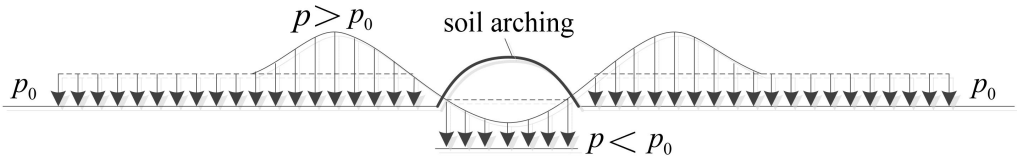

(b)

Figure 9. Illustration of the principle of soil arching effect: (a) Diagram of forming the horizontal soil arching. (b) Diagram of stress redistribution.

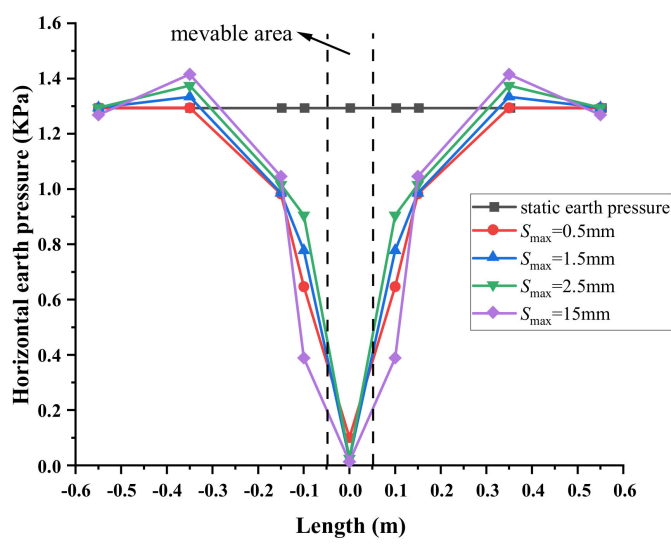

(a)

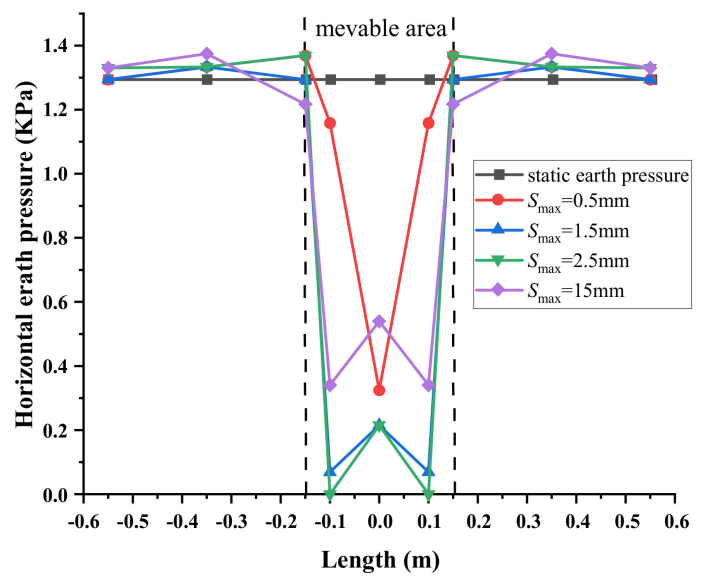

(c)

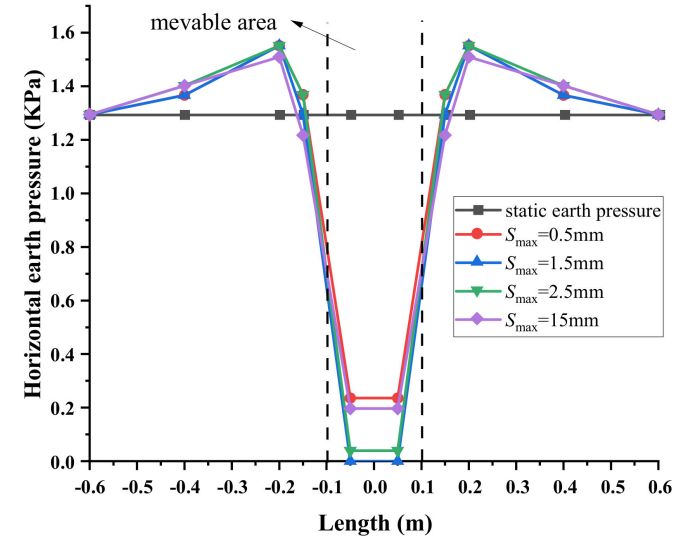

(b)

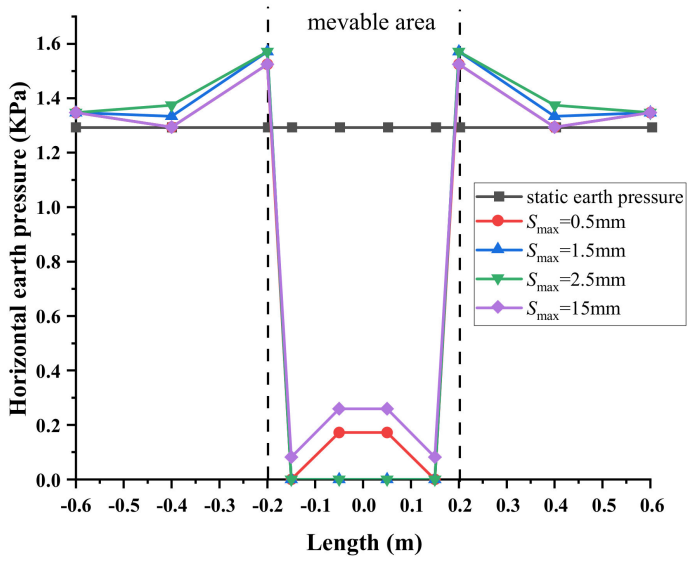

(d)

Figure 10. The distribution of earth pressure along the $\mathrm{X}$ axis with different trap-door widths in RB-mode: (a) $w / H=0.2,(\mathbf{b})$ $w / H=0.4,(\mathbf{c}) w / H=0.6,(\mathbf{d}) w / H=0.8$. 


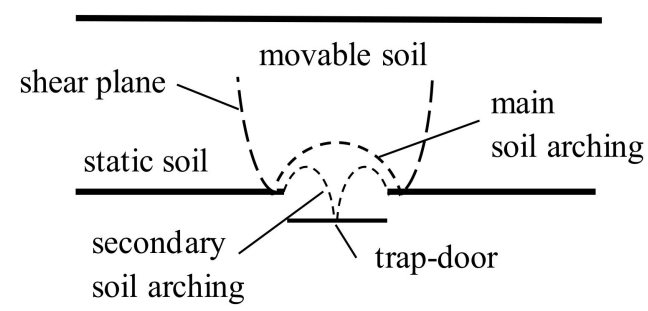

Figure 11. Secondary soil arching effect.

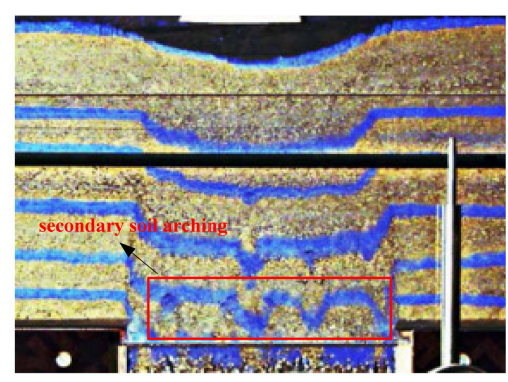

Figure 12. Trap-door test of Chevalier et al. [20].

\subsection{Distribution of Lateral Earth Pressure in RT Mode}

The distribution of the lateral earth pressure along the $X$ axis in RT mode is plotted in Figure 13. Similar to T and RB modes, when the trap-door produced an active displacement of rotation around the top, the earth pressure behind the fixed wall slightly increased and exceeded the static earth pressure. However, the earth pressure on the trap-door decreased greatly with the minimum value close to 0 . However, it should be mentioned that the minimum lateral soil pressure under some displacement (i.e., the displacement in Figure $13 \mathrm{~b}-\mathrm{d}$ ) was not located at the middle of the movable plates, but the positions of a side edge. This illustrated that the 'secondary soil arching effect' also existed in RT mode.

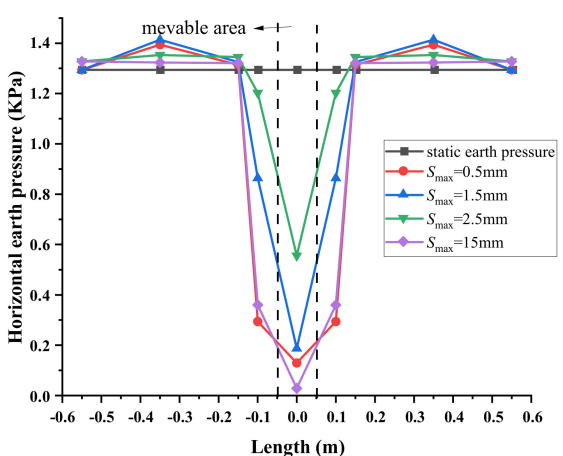

(a)

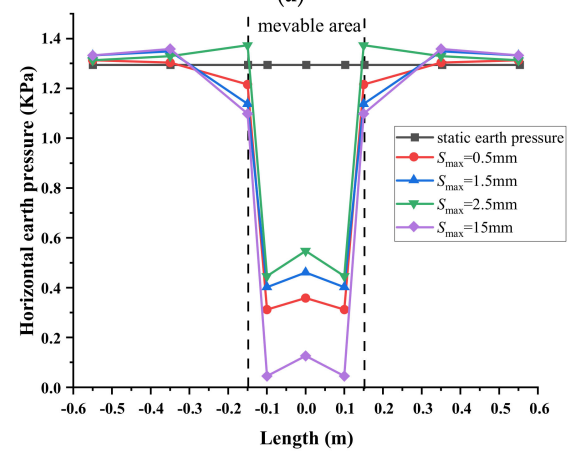

(c)

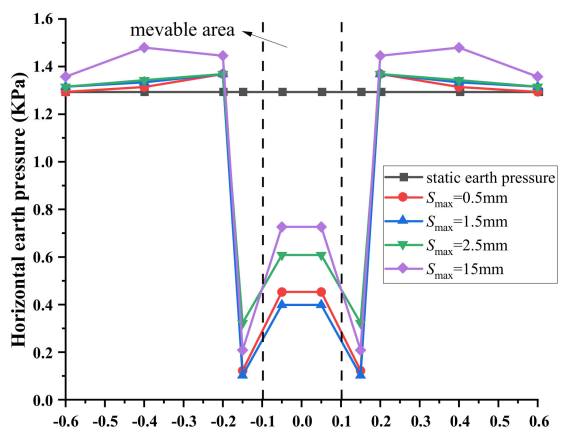

Length (m)

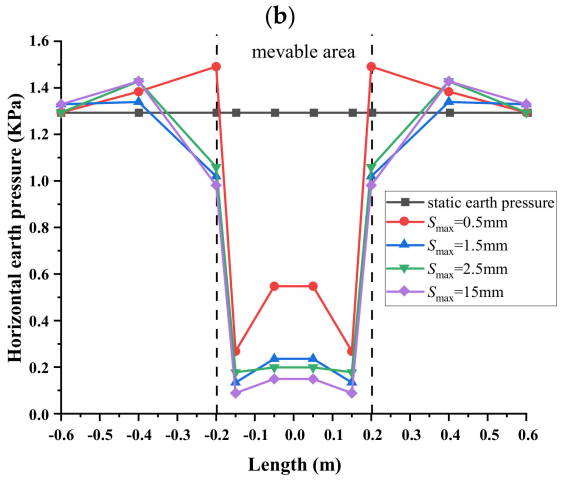

(d)

Figure 13. The distribution of earth pressure along the $X$ axis with different trap-door widths in RT-mode: (a) $w / H=0.2,(\mathbf{b}) w / H=0.4,(\mathbf{c}) w / H=0.6,(\mathbf{d}) w / H=0.8$. 


\subsection{Variation of Horizontal Earth Pressure with the Displacement of Trap-Door}

To explore the variation pattern of horizontal earth pressure with the distance of the trap-door under different movement modes, the earth pressure on the moveable plate with a width of $10 \mathrm{~cm}$ was selected for analysis. To be convenient, the horizontal earth pressure acting on the trap-door was marked as $\sigma_{h}$. And the height of the load cell on the trap-door above the bottom was marked as $h$ (see Figure 3).

The variation of the horizontal soil pressure at different heights versus displacement in three modes is shown in Figure 14. According to Fang and Ishibashi [4] and Chen [30], the earth pressure behind the rigid wall might reach its minimum at the active displacement of about $0.1 \sim 0.2 \% H$, which means that the soil reached a limited state. However, it is clear from Figure 14 that the lateral soil pressure did not remain at a stable value in the soil limited state, but increased to a larger value for the displacement overpassing $0.1 \sim 0.2 \% H$. The variation of total earth pressure could be divided into three stages:

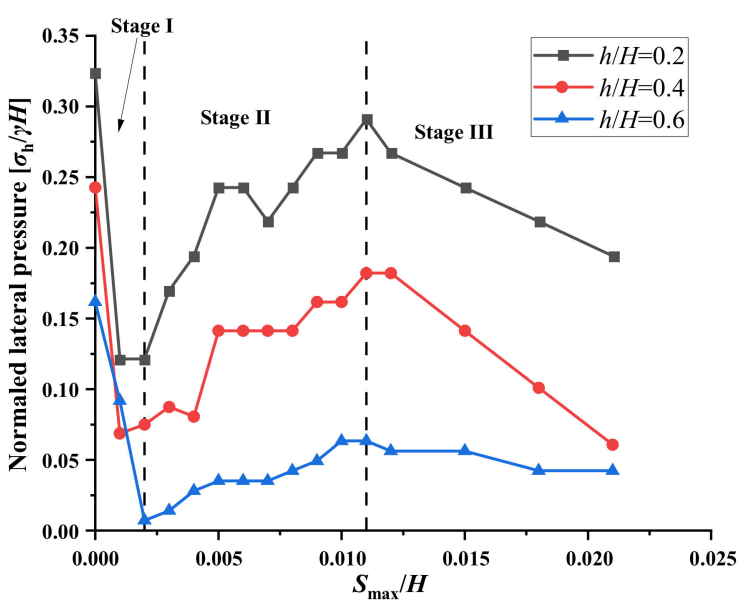

(a)

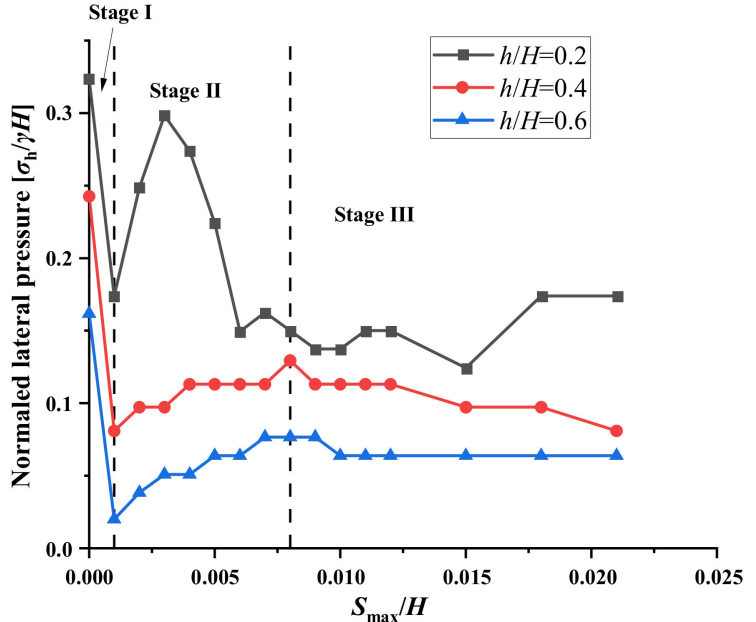

(b)

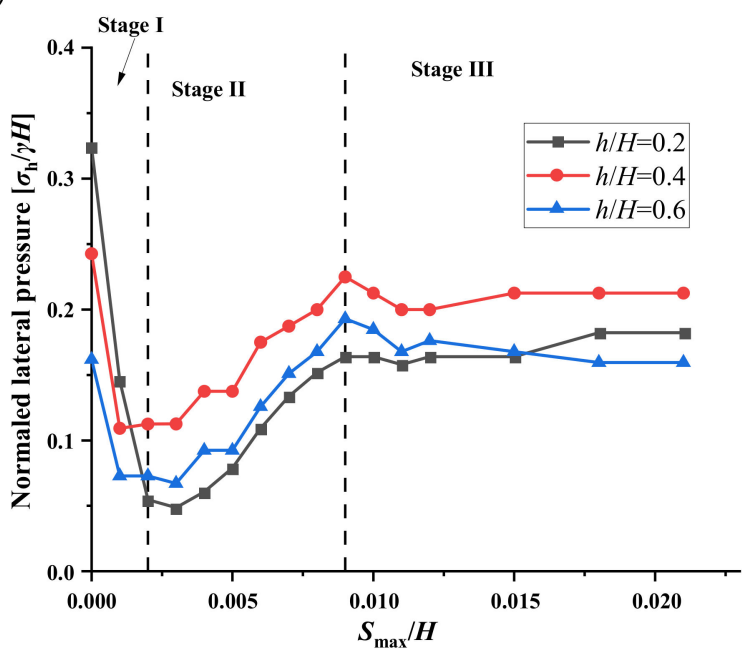

(c)

Figure 14. Variation of active earth pressure behind the moveable plate with the movement of moveable plates in three modes: (a) T mode, (b) RB mode, (c) RT mode.

Stage I: Reduction stage of earth pressure behind the moveable plate. For any movement mode, the earth pressure behind the trap-door is reduced from the static pressure to the active pressure in this stage. As shown in Figure 14, the lateral soil pressure reached the minimal value when the displacement of the trap-door was about $0.1 \sim 0.2 \% H$ in the three modes. The limited displacement obtained from the test was similar to Fang [4] and Chen [30]. 
Stage II: Increasing stage of earth pressure behind the moveable plate. Unlike the classical earth pressure theory, the earth pressure would rise sharply with the movement of plates instead of maintaining a stable state. Furthermore, the pressure peak in the three modes was lower than the static soil pressure.

Stage III: Stable stage of earth pressure behind the moveable plate. During this stage, the earth pressure converges to a stable state. The present tendency was in good agreement with those given by Chevalier [20], and Bosscher and Gray [25]. It should be mentioned that the maximum stable pressure in RT mode was located at the middle height of the wall. Because the displacement was larger in the lower location in RT mode, the earth pressure would decrease more at the bottom part of the wall. However, the lower location corresponded to a larger gravity, therefore the stable earth pressure eventually emerged in the middle of the trap-door.

Similar to that in the vertical trap-door experiment, the above phenomenon of pressure variation could be explained by the theory of soil arching evolution [17-19], as shown in Figure 15. When the displacement of the trap-door was small, the initial soil arch formed and the earth pressure decreased to a minimum. At this time, the soil mass reached the active limit equilibrium state and the soil arching effect was fully exerted. After that, with the increasing displacement of the trap-door, the slide plane gradually extended to the interior of the soil. Then, the initial soil arch was destroyed and the earth pressure increased. Finally, a stable soil arch was formed again in the soil and the earth pressure gradually decreased to a stable value. Particularly, in addition, to the horizontal displacement of the soil, there was also an impact caused by gravity and different displacement modes, therefore the strength of the soil arching at various heights was disparate.

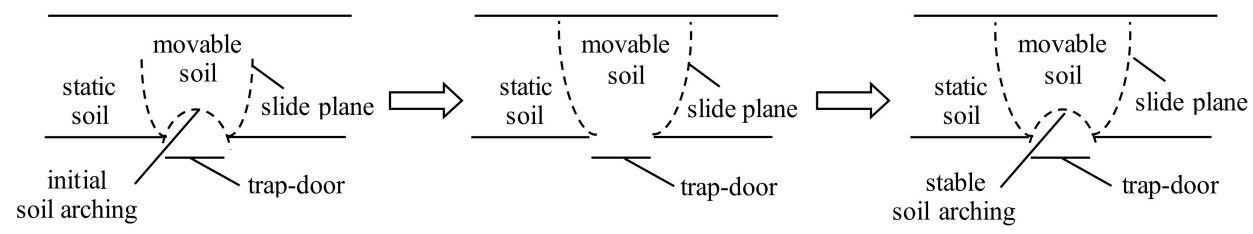

Figure 15. Diagram of soil arching evolution.

\subsection{Influence of the Trap-Door Width}

To investigate the influence of trap-door width, the maximal earth pressure acting on the model box wall at $30 \mathrm{~cm}$ height was selected for analysis, which was marked as $p_{\max }$. To be conveniently compared, the static earth pressure at a $30 \mathrm{~cm}$ height was noted as $p_{0}$. The range where the earth pressure change was influenced by the movement of trap-door is denoted as $B$. The tendency of $p_{\max }$ and $B$ varying with the trap-door width is indicated in Figure 16.

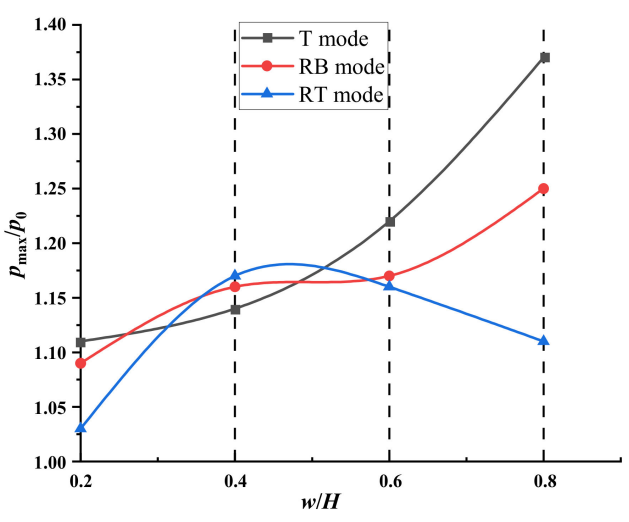

(a)

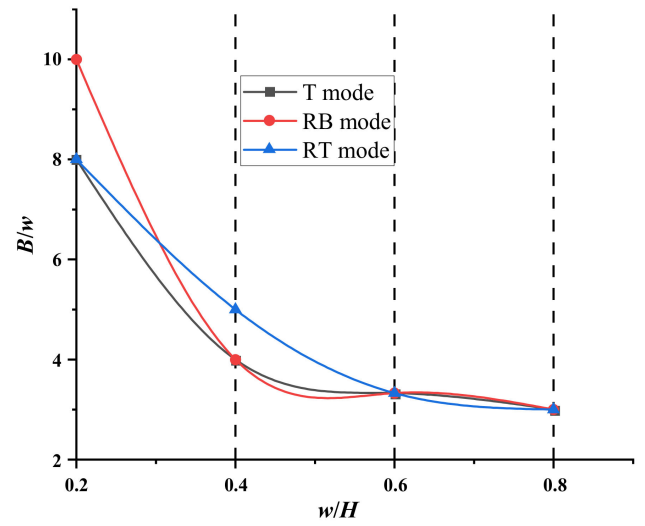

(b)

Figure 16. $p_{\max }$ and $B$ varying with trap-door width. (a) Relation between $p_{\max } / p_{0}$ and $w / H$. (b) Relation between $B / w$ and $w / H$. 
It can be observed from Figure 16a that the peak load acting on the fixed wall increased with the width of the trap-door expanding for T and RT mode. However, for RT mode, it increased when $w / H$ was less than 0.43 and then descended gradually. The maximal value of $p_{\max } / p_{0}$ was about 1.37 , emerging on $\mathrm{T}$ mode at $w / H=0.8$. It is evident that the exertion degree of the soil arching effect was strongest in T mode, followed by RB mode, and was weakest in RT mode.

The variation of $B / w$ as a function of $w / H$ is presented in Figure 17. It is clear from Figure $16 \mathrm{~b}$ that $B / w$ decreased with the increasing value of $w / H$ for the three movement modes. For most cases, the $B / w$ was from 3 to 5 . From the analysis above, the $p_{\max } / p_{0}$ and $B / w$ were mainly influenced by the width of the trap-door. Thereby, for the partial-displacement retaining wall, the increase in the extra load transferred from the moveable wall to the adjacent fixed wall would be controlled by the movement range and displacement amount.

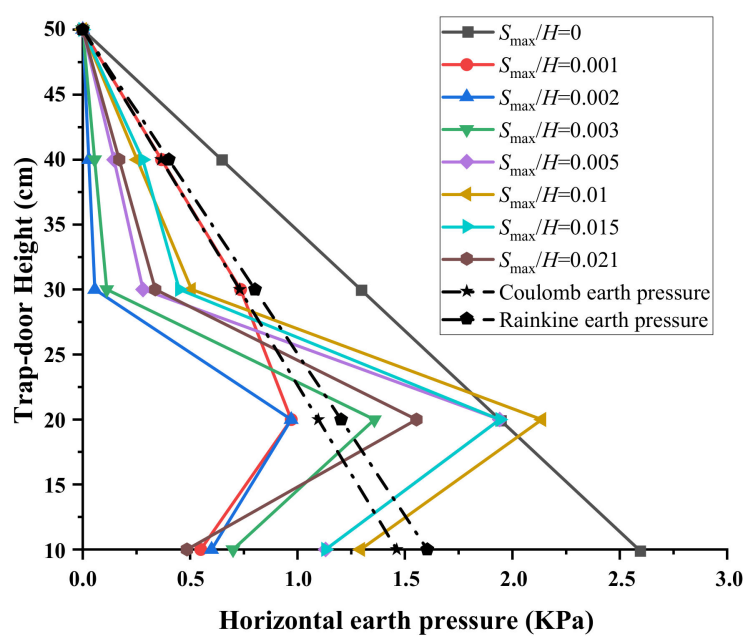

(a)

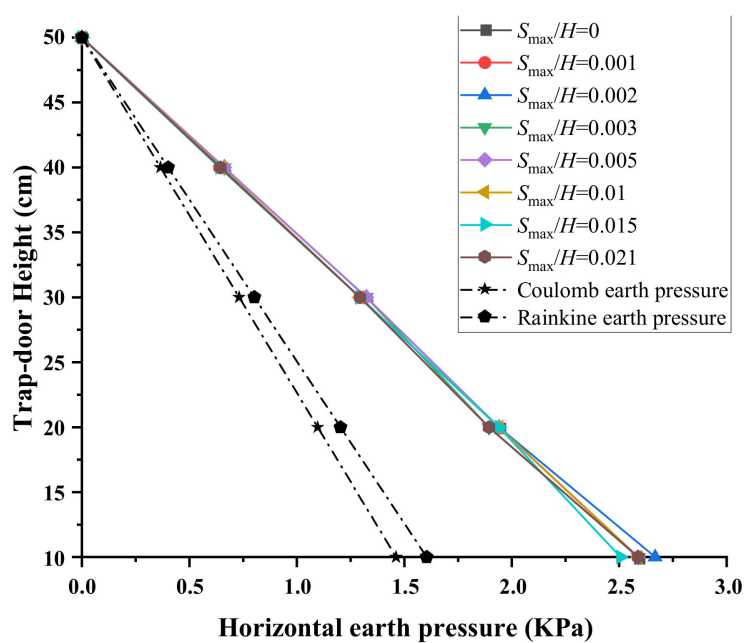

(b)

Figure 17. Distribution of earth pressure on the trap-door and fixed wall in T mode: (a) earth pressure on the trap-door, (b) earth pressure on the fixed wall.

\subsection{Distribution of Earth Pressure along the Height}

To reveal the distribution of earth pressure along the height of thee moveable plates, earth pressure exertion on the moveable plate under the test condition of a $10 \mathrm{~cm}$ trap-door width was plotted. For comparison, the data from load cells on the fixed wall located at $x=0.35 \mathrm{~m}$ was also selected for analysis.

Figures 17-19 show the distribution of active earth pressure along the height of the trap-door and fixed wall in different displacement modes. It appeared that the distribution of horizontal earth pressure along the height of the trap-door was obviously nonlinear. Its nonlinearity performed that the lateral soil pressure near the middle of the trap-door had a significant increase, which was similar to the research of Fang and Ishibashi [4]. The horizontal earth pressure on the fixed wall at the location of $x=0.35 \mathrm{~m}$ was slightly larger than the static earth pressure when the trap-door produced displacement. The distribution of earth pressure on the fixed wall basically presented a linear-distribution along the height.

Compared with the condition of movement of the entire retaining wall, only the movable plates had a displacement in the horizontal trap-door test, while the surrounding box wall was fixed. Thus, it was evident that the horizontal soil arching phenomenon dominated the backfill performance behind the trap-door, making the earth pressure distribution different with traditional soil pressure. 


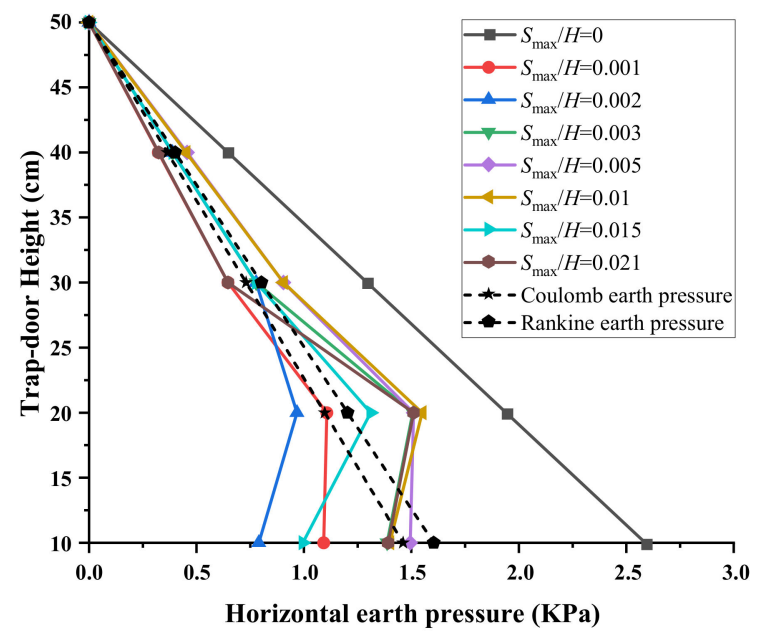

(a)

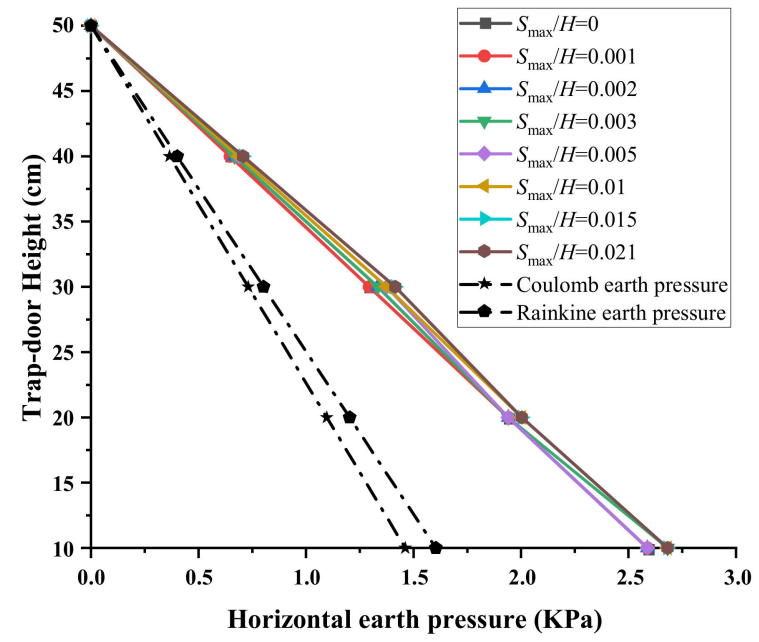

(b)

Figure 18. Distribution of earth pressure on the trap-door and fixed wall in RB mode: (a) earth pressure on the trap-door, (b) earth pressure on the fixed wall.

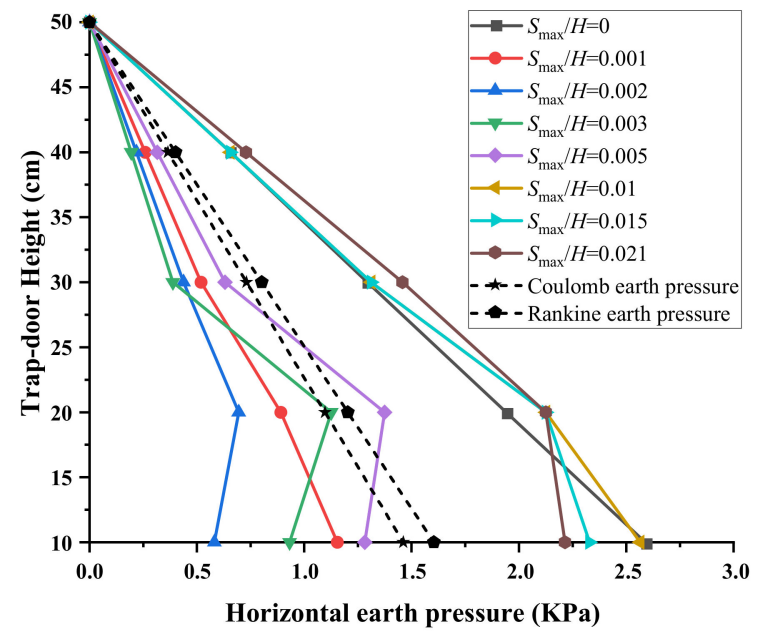

(a)

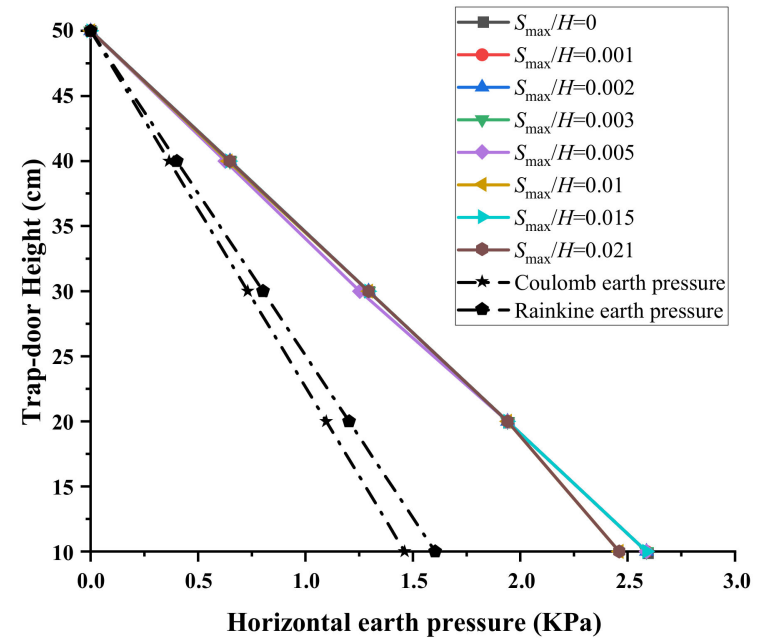

(b)

Figure 19. Distribution of earth pressure on the trap-door and fixed wall in RT mode: (a) earth pressure on the trap-door, (b) earth pressure on the fixed wall.

The active earth pressure coefficient is defined as:

$$
K_{a}=P /\left(\frac{1}{2} \gamma H^{2}\right)
$$

where $P$ is the resultant force of the horizontal earth pressure acting on the trap-door, and $\gamma$ is the bulk density of the filler.

The variation of the active earth pressure coefficient corresponding to the displacement of the trap-door is shown in Figure 20. It showed a distinct nonlinear relationship of $K_{a}$ and $S_{\max } / H$. The active earth pressure coefficient in the three modes all decreased rapidly at first, and then increased gradually with the increasing displacement, and reached a stable value eventually. This tendency was similar to the variation in active earth pressure. The ultimate active earth pressure coefficient was less than Coulomb and Rankine theory in $\mathrm{T}$ and RB mode, which equaled about 0.15 . However, the active earth pressure coefficient in RT mode at any displacement was a little greater than Coulomb active earth pressure coefficient and its stable value could reach about 0.26 . 


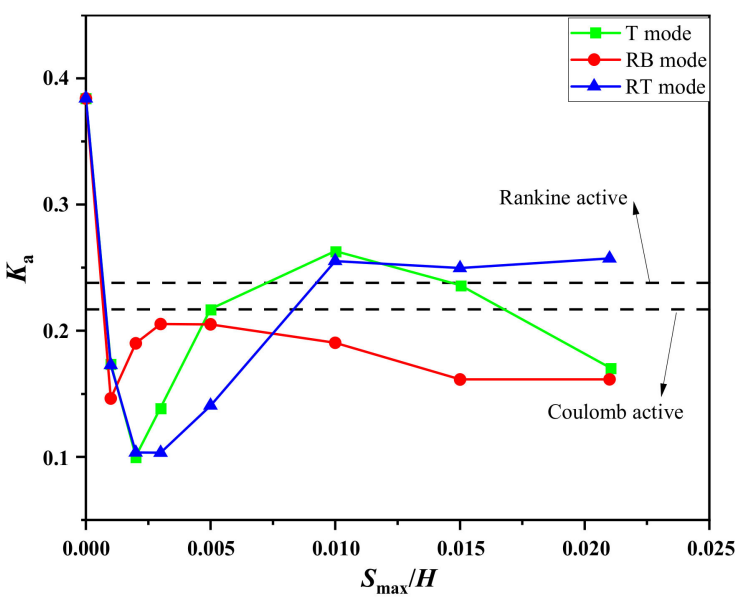

Figure 20. Distribution of active earth pressure coefficient with displacement of the trap-door.

\subsection{Load Sharing Ratio}

It should be mentioned from the above data that when the trap-door produced movement, the load sharing effect generated between the movable plate and the model box wall. In this section, the study of load sharing was established based on the data of the horizontal trap-door test. The load sharing ratio is defined as $n$, as expressed in Equation (3).

$$
n=\frac{P_{\text {door }}}{P_{\text {wall }}}
$$

where $P_{\text {door }}$ is calculated by summing the earth pressure acting on the trap-door in each test condition, and $P_{\text {wall }}$ is the resultant earth pressure on the fixed wall within the same width of the movable plates.

Analysis of the load sharing ratio $n$ in Figure 21 showed that the maximal $n$ of all displacement modes occurred at the $10 \mathrm{~cm}$ wide trap-door. The load sharing ratio had a minimum value at $w / H=0.4$ in T mode while $w / H=0.8$ in RT and RB modes. The minimal load sharing ratio usually tends to be sought because the lower load sharing ratio showed that the moveable wall undertook less load, which is favorable to the stability of retaining wall. It is clear from the figure that $n$ reached the minimum at a specific displacement and did not decrease continuously as displacement increased. The minimum was about 0.1 in the three modes.

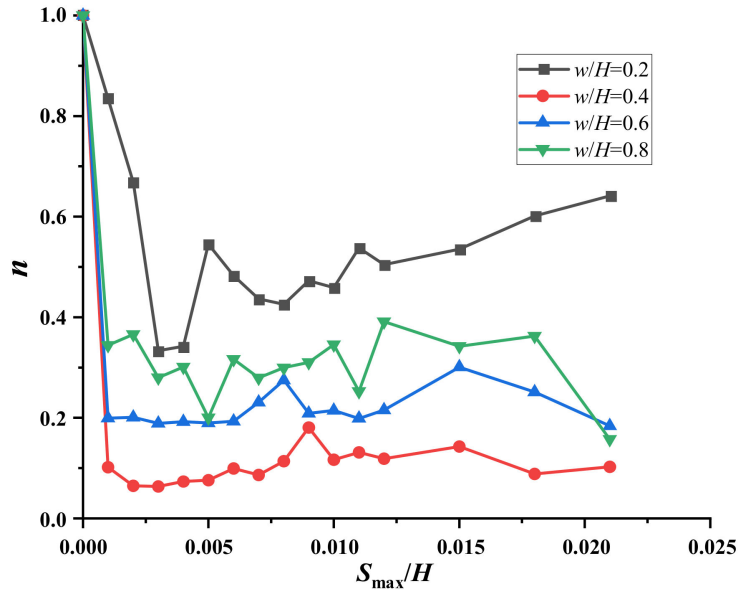

(a)

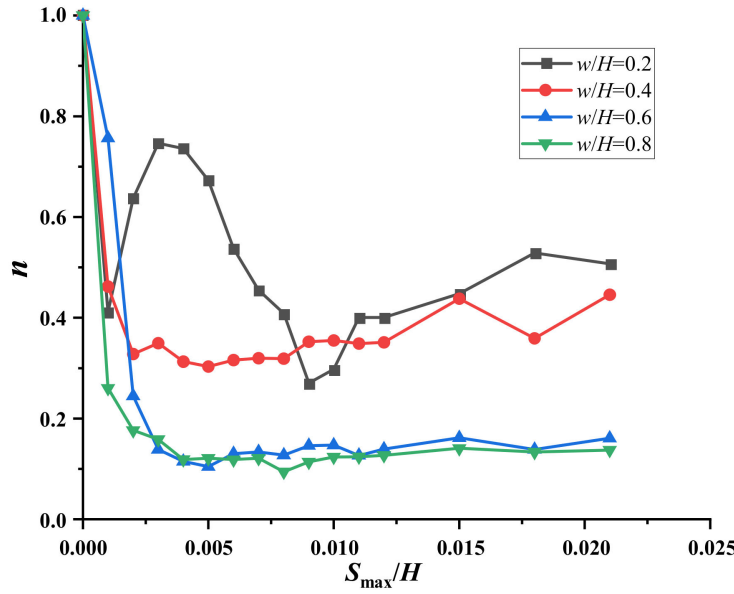

(b)

Figure 21. Cont. 


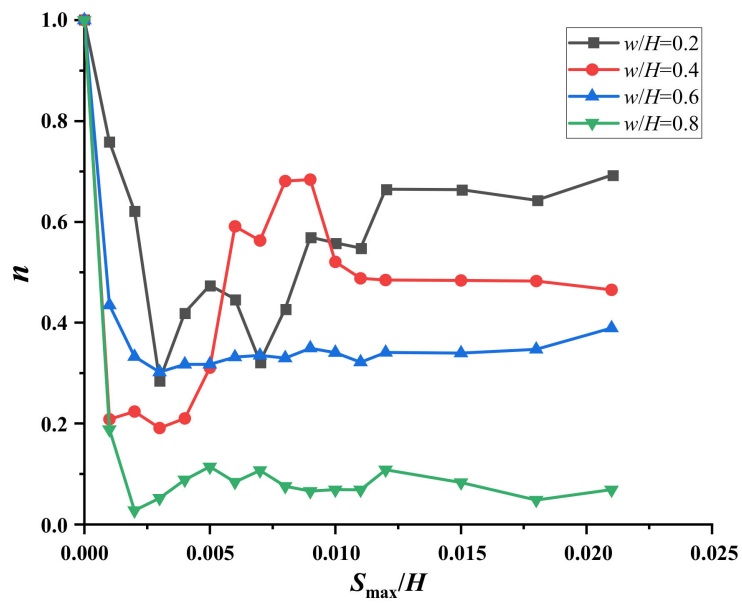

(c)

Figure 21. Variation of load sharing ratio in different modes: (a) T mode, (b) RB mode, (c) RT mode.

\section{Conclusions}

A horizontal trap-door experiment was conducted to research the active earth pressure distribution under different displacement modes and widths. The influence of the soil arching effect on the distribution of earth pressure was studied and the relationship of displacement and earth pressure was also investigated. Some conclusions obtained are listed as follows:

The horizontal soil arching effect was generated after the active displacement of the trap-door. The existence of soil arching greatly reduced the earth pressure behind the trap-door and enlarged it on the box wall to exceed the static earth pressure. For the trap-door widths of $20 \mathrm{~cm}, 30 \mathrm{~cm}$, and $40 \mathrm{~cm}$, there may be a secondary soil arching effect.

The variation of earth pressure with displacement amount indicated a tendency of decreasing first, then increasing and finally tending to be stable. This variation was divided into three phases corresponding to the evolution of soil arching.

The distribution of active earth pressure varied with displacement along the height of the trap-door, showing obvious non-linearity. The active earth pressure in RT mode was larger than the Rankine or Coulomb earth pressure while it was smaller in T and RB modes.

Analysis of the load sharing ratio showed that the minimum was reached at a relatively small displacement, then was not significantly reduced as the displacement increased. The width of the moveable wall to reach the minimum was not the same in different displacement modes.

It should be mentioned that this test did not consider the theory to calculate the earth pressure distribution caused by the partial displacement of the retaining wall, so further theory analysis may need to be induced to study the distribution of earth pressure and the soil arching effect.

Author Contributions: Conceptualization, H.Z.; writing-original draft preparation, M.L.; funding acquisition, P.Z., X.L., and X.X. writing-review and editing, Z.Z. and X.S. All authors have read and agreed to the published version of the manuscript.

Funding: This paper was supported in part by the Key Research and Development Program of Shandong Province (No. 2019GSF109045), in part by the Qilu Young Scholar Program of Shandong University (201999000171).

Institutional Review Board Statement: Not applicable.

Informed Consent Statement: Not applicable.

Data Availability Statement: Data sharing not applicable.

Conflicts of Interest: The authors declare no conflict of interest. 


\section{References}

1. Zhang, S.M.; Yuan, T.K.; Zhou, Y.K.; Li, D.H.; Zhuo, K.H. The Research Review of Underground Continuous Wall on Deformation Characteristic. Appl. Mech. Mater. 2014, 580, 224-230. [CrossRef]

2. Clough, G.W.; O'Rourke, T.D. Construction induced movements of in situ walls. In Proceedings of the Specialty Conference on Design and Performance of Earth Retaining Structures, ASCE Special Conference, Ithaca, NY, USA, 18-21 June 1990; pp. 439-470.

3. Fang, Y.; Chen, T.; Wu, B. Passive Earth Pressures with Various Wall Movements. J. Geotech. Eng. 1994, 120, 1307-1323. [CrossRef]

4. Fang, Y.; Ishibashi, I. Static Earth Pressures with Various Wall Movements. J. Geotech. Eng. 1986, 112, 317-333. [CrossRef]

5. Benmebarek, N.; Labdi, H.; Benmebarek, S. A Numerical Study of the Active Earth Pressure on a Rigid Retaining Wall for Various Modes of Movements. Soil Mech. Found. Eng. 2016, 53, 39-45. [CrossRef]

6. Cui, B.B. Soil Arching Effect and Distribution of Earth Pressure under Different Displacement Modes. Master's Thesis, Shandong University, Jinan, China, 2018. (In Chinese).

7. Terzaghi, K.; Peck, R.B.; Mesri, G. Soil Mechanics; John Wiley \& Sons: New York, NY, USA, 1996.

8. Li, M.-G.; Chen, J.-J.; Wang, J.-H. Arching effect on lateral pressure of confined granular material: Numerical and theoretical analysis. Granul. Matter 2017, 19, 20. [CrossRef]

9. Liang, R.; Zeng, S.; Robert, L.; Sanping, Z. Numerical Study of Soil Arching Mechanism in Drilled Shafts for Slope Stabilization. Soils Found. 2002, 42, 83-92. [CrossRef]

10. Zhang, H.; Wang, H.; Li, X.; Li, W.; Wu, J.; Lv, C.; Song, X.; Liu, M. An Analysis of Floating Geogrid-Reinforced Pile-Supported Embankments Containing Deep Softened Soil. Arab. J. Sci. Eng. 2021, 1-14. [CrossRef]

11. Terzaghi, K. Stress distribution in dry and in saturated sand above a yielding trapdoor. In Proceedings of the International Conference of Soil Mechanics and Foundation Engineering, Cambridge, MA, USA, 22-26 June 1936; pp. $307-311$.

12. McNulty, J.W. An Experimental Study of Arching in Sand; University of Illinois Urbana-Champaign: Urbana-Champaign, IL, USA, 1965.

13. Ladanyi, B.; Hoyaux, B. A Study of the Trap-Door Problem in a Granular Mass. Can. Geotech. J. 1969, 6, 1-14. [CrossRef]

14. Pardo, G.; Sáez, E. Experimental and numerical study of arching soil effect in coarse sand. Comput. Geotech. 2014, 57, 75-84. [CrossRef]

15. Handy, R.L. The Arch in Soil Arching. J. Geotech. Eng. 1985, 111, 302-318. [CrossRef]

16. Adachi, T. Trap door experiment under centrifugal conditions. In Deformation and Progressive Failure in Geomechnics; Elsevier: Amsterdam, The Netherlands, 1997; pp. 725-730.

17. Dewoolkar, M.M.; Santichaianant, K.; Ko, H.-Y. Centrifuge Modeling of Granular Soil Response overactive Circular Trapdoors. Soils Found. 2007, 47, 931-945. [CrossRef]

18. Papamichos, E.; Vardoulakis, I.; Heil, L. Overburden modeling above a compacting reservoir using a trap door apparatus. Phys. Chem. Earth Part A Solid Earth Geod. 2001, 26, 69-74. [CrossRef]

19. Iglesia, G.R.; Einstein, H.H.; Whitman, R.V. Investigation of Soil Arching with Centrifuge Tests. J. Geotech. Geoenviron. Eng. 2014, 140, 4013005. [CrossRef]

20. Chevalier, B.; Combe, G.; Villard, P. Experimental and discrete element modeling studies of the trapdoor problem: Influence of the macro-mechanical frictional parameters. Acta Geotech. 2012, 7, 15-39. [CrossRef]

21. Wang, W.L.; Yen, B.C. Soil Arching in Slopes. J. Geotech. Eng. Div. 1974, 100, 61-78. [CrossRef]

22. Kahyaoğlu, M.R.; Onal, O.; Imançli, G.; Ozden, G.; Kayalar, A.Ş. Soil arching and load transfer mechanism for slope stabilized with piles. J. Civ. Eng. Manag. 2012, 18, 701-708. [CrossRef]

23. He, G.; Xu, J.; Jiang, J.; Cao, Z.; Zhu, D. Soil arching effect analysis and structure optimization of a robot foot sinking in soft soil. Adv. Mech. Eng. 2017, 9, 1-9. [CrossRef]

24. Chen, C.-Y.; Martin, G. Soil-structure interaction for landslide stabilizing piles. Comput. Geotech. 2002, 29, 363-386. [CrossRef]

25. Bosscher, P.J.; Gray, D.H. Soil Arching in Sandy Slopes. J. Geotech. Eng. 1986, 112, 626-645. [CrossRef]

26. Li, C.; Tang, H.; Hu, X.; Wang, L. Numerical modelling study of the load sharing law of anti-sliding piles based on the soil arching effect for Erliban landslide, China. KSCE J. Civ. Eng. 2013, 17, 1251-1262. [CrossRef]

27. Huang, Z.-Y.; Zhang, Y.-X.; Dong, J. Experimental study of soil arching and transfer behavior of earth pressure about sheet-pile walls. Rock Soil Mech. 2013, 34, 1887-1892. (In Chinese)

28. Bakri, M.; Xia, Y.; Wang, H. Load sharing of anti slide piles based on three dimensional soil arching numerical analysis. Electron. J. Geotech. Eng. 2014, 19, 17573-17590.

29. Ministry of Transport, People's Republic of China. GB/T 50123-2019 Standard for Geotechnical Testing Method; People's Communications Publishing House: Beijing, China, 2019. (In Chinese)

30. Yekai, C.; Riqing, X.; Xiaojun, Y.; Xiaonan, G. A new method calculating earth pressure on flexible structures for excavation work. Ind. Constr. 2001, 3, 1-4. (In Chinese) 